\title{
Efficacy of switching from infliximab to golimumab in patients with ulcerative colitis in deep remission
}

\author{
N. Viazis 1 , C. Pontas ${ }^{1}$, A. Manolakis ${ }^{1}$, G. Karampekos ${ }^{1}$, E. Tsoukali ${ }^{1}$, M. Galanopoulos ${ }^{1}$, K. Koustenis ${ }^{1}$, E. Archavlis ${ }^{1}$, A. \\ Christidou $^{1}$, M. Gazouli², G. J. Mantzaris ${ }^{1}$ \\ (1) Gastroenterology Department, General Hospital of Athens 'Evangelismos-Ophthalmiatreion Athinon-Polykliniki', Athen, Greece ; (2) Department of Basic Medical \\ Sciences, Laboratory of Biology Medical School, National and Kapodistrian University of Athens, Athens, Greece.
}

\begin{abstract}
Background-Aim: Intravenously administered biologicals are associated with a huge pressure to Infusion Units and increased cost. We aimed to assess the impact of switching infliximab to golimumab in ulcerative colitis (UC) patients in deep remission.

Patients and method: In a prospective, single-centre pilot study UC patients on infliximab mono-therapy for $\geq 2$ years, whowere in deep remission, consented to switch to golimumab and were followed for 1 year with clinical assessment, serum and faecal biomarkers, work productivity, satisfaction with treatment and quality of life parameters. Endoscopic remission was assessed by colonoscopy at 1 year. Patients fulfilling the same inclusion criteria, who did not consent to switch to golimumab and continued to receive infliximab mono-therapy, for the same period, served as controls.

Results: Between October 2015 and October 2017, 20 patients were recruited; however one patient stopped therapy because of pregnancy. All 19 patients who were switched to golimumab were still in clinical, biomarker and endoscopic remission at 1 year and maintained excellent quality of life without any complications. In the control group, 18 of 19 patients were also in deep remission, since only one patient had a flare which was managed with IFX dose intensification. During a median 3 years extension treatment with golimumab only 2 patients experienced a flare of colitis.

Conclusions: This pilot study indicates that switching from in-fliximab to golimumab in $\mathrm{UC}$ patients in deep remission does not compromise treatment effectiveness or the course of disease; golimumab offers a valid alternative to intravenous infliximab infusions during the COVID-19 pandemic. (Acta gastroenterol. belg., 2021, 84, 423-428).
\end{abstract}

Key words: Ulcerative colitis, infliximab, golimumab.

\section{Introduction}

Ulcerative colitis (UC) is a chronic idiopathic inflammatory bowel disease (IBD) which almost exclusively affects the colonic mucosa. In recent years therapy has shifted from mere control of symptoms towards a more global control of inflammation by achieving and maintaining long-term clinical remission, normalization of objective (serological and faecal) biomarkers of inflammation, endoscopic and potentially histologic remission (1). This composite definition of remission (namely 'complete' or 'deep' remission) may be associated with improved long-term outcomes of disease, i.e. prevention of complications, hospitalizations and colectomy, avoidance of disability and maintenance of at least near-normal quality of life of patients (2). The advent of biological therapies, namely anti-TNFs, antiintegrins and anti-IL12/IL23, has dramatically increased the therapeutic potential to achieve and maintain these targets (3).

The European Agency for Medicines (EMA) has approved three anti-TNF agents for the treatment of moderate-to-severe UC, infliximab (IFX) for intravenous (iv) administration and adalimumab (ADA) and golimumab (GLM) for subcutaneous (sc) administration. In randomized controlled and observational studies all these agents have proven efficacious in achieving and maintaining remission of active moderate-to-severe $\mathrm{UC}$; in addition, IFX is an effective rescue therapy for patients with acute severe UC who have failed first line therapy with iv corticosteroids (4-10). With the expanding use of anti-TNFs and other biologicals, medication therapy has replaced hospitalizations and surgeries as the major cost driver in the field of IBD (11). In a recent analysis of treatment costs in the USA, based on insurance claims data, adjusted annualized healthcare costs for anti-TNFs among UC patients was calculated to sum up to a median (confidence interval) amount of $\$ 51,429$ (49,176-53,682) (12). Although no study has directly compared direct costs between the intravenously and the subcutaneously administered anti-TNFs, a recent systematic review, including seventy articles, yielded conflicting results, since ADA seemed more cost-effective compared to IFX as maintenance therapy for moderate to severe Crohn's disease (CD) and IFX seemed more costeffective than ADA in moderate-to-severe UC (13).

Because ADA and GLM can be self-administered, switching from IFX to GLM in UC patients maintained in prolonged deep remission for convenience, avoidance of patient exposure to the hospital environment, reduction of absenteeism rates, cutting hospital budgets and relieving the burden in infusion clinics is a strategy worth exploring. Thus, we performed a prospective pilot study to assess the effectiveness and direct cost of switching from IFX to sc GLM UC patients in prolonged deep remission. Secondary objective was the safety of GLM scheduled therapy.

\footnotetext{
Correspondence to : Nikos Viazis MD, 31 $1^{\text {st }}$ street, number 11, Elliniko, 16777, Athens, Greece. Phone : +302132041609. Fax : +302132041634

E-mail: nikos.viazis@gmail.com

Submission date : 20/08/2020

Acceptance date : $14 / 02 / 2021$
} 


\section{Methods}

Design of the study - inclusion and exclusion criteria

This was a prospective, single-center, pilot study. We enrolled consecutive patients with $\mathrm{UC}, \geq 18$ years of age, diagnosed according to established criteria (14), who were receiving scheduled maintenance IFX monotherapy at approved doses ( $5 \mathrm{mg} / \mathrm{kg}$ every 8 weeks $)$ for at least 2 years and were in deep remission. and, This was defined as the combination of clinical and endoscopic remission (total Mayo score $\leq 2$, with no individual subscore higher than 1), normal haematological and faecal inflammatory biomarkers (complete blood count (CBC), erythrocyte sedimentation rate (ESR), C-Reacting Protein (CRP) and faecal calprotectin (FCal)) In all patients, at baseline, the extent of disease was determined using the Montreal classification (15) and global disease activity was graded according to the total Mayo score (16).

Patients were excluded if they had active disease, were receiving combination therapy with azathioprine or another biologic agent or had received GLM in the past, had experienced any allergic reaction to IFX or had signs of active infection.

\section{Patients and laboratory parameters}

On the day of their scheduled IFX infusion, after a thorough discussion on the pros and cons of the protocol with one of the investigators (GJM), patients fulfilling the entry criteria were asked to consent either to switch to GLM or continue IFX treatment. Patients who opted to switch did not receive the scheduled dose of IFX and immediate treatment with GLM was planned. In contrast, patients who did not consent continued to receive IFX as before. Of the latter, patients matched for age, gender, extent of UC and duration of treatment with the patients who were switched to GLM were selected to serve as a control group.

Before any treatment trough IFX levels were measured in all patients irrespective of whether they continued IFX or switched to GLM using an ELISA method (ELISA; Eagle Biosciences, Nashua, New Hampshire, USA). The lower limit of quantification for IFX trough levels was $0.03 \mu \mathrm{g} / \mathrm{ml}$.

\section{Patients switched to GLM}

GLM was administered according to approved dosing regimen (induction with $200 \mathrm{mg}$ and $100 \mathrm{mg}$ sc at weeks 0 and 2, respectively, followed by monthly scheduled maintenance treatment with $50 \mathrm{mg}$ or $100 \mathrm{mg}$ for patient body weight $<80 \mathrm{Kg}$ or $\geq 80 \mathrm{Kg}$, respectively). Only concomitant therapy with oral 5-ASA was permitted during the course of the study. Co-treatment with corticosteroids and/or azathiorpine was not permitted; however, GLM dose intensification was allowed in patients experiencing loss of response (reappearance of symptoms of active UC in association with elevation of CRP and/or FCal, in the absence of any infection, such as clostridium difficile or cytomegalovirus) during the study period.

Patients were assessed in the outpatient IBD Clinic at 6 and 12 months after enrollment. At each visit, the course of disease was assessed using the partial Mayo score and physical examination was performed including records of the body weight and body mass index. Routine laboratory tests were performed (CBC, ESR, CRP, FCal, Liver Function Tests (LFTs), serum urea, creatinine, glucose and electrolytes). FCal was measured using a point-of care assay (Buhlmann, SchönenbuchSwitzerland). Values $\leq 150 \mu \mathrm{g} / \mathrm{g}$ faecal tissue were considered compatible with clinical remission, based on available evidence when this study was designed that FCP levels higher than $200 \mu \mathrm{g} / \mathrm{g}$ or $300 \mu \mathrm{g} / \mathrm{g}$, respectively, in patients with clinical quiescent UC, could identify patients at a higher risk for relapse of disease $(17,18)$.

In addition, patients were asked to complete an adverse event list and questionnaires regarding quality of life (short Inflammatory Bowel Disease Questionnaire (19)), disability, work productivity (Work Productivity and Activity Impairment Questionnaire (20)) and satisfaction with the treatment (Greek TSQM (21)). At 12 months, patients were re-endoscoped to assess maintenance of endoscopic remission. Extra visits were arranged by telephone or face-to-face for patients with symptoms compatible with a flare of UC; if a flare was confirmed and other mimickers of UC flare were excluded patients were withdrawn from the study.

Patient clinical evaluation, laboratory tests, prescription refills and distribution of questionnaires were performed by two independent physicians who were unaware that patients had been included in a clinical trial, as regular filling of quality parameters is part of our routine practice in the outpatient IBD Clinic. Colonoscopy at the end of the study was also performed by an experienced endoscopist unaware that the patients participated in a clinical trial or their treatment. Patients who completed successfully the annual follow up were asked to continue treatment with GLM and were followed with regular visits in the Outpatient Clinic until this study was closed. Patients in the long-term extension study were followed prospectively, using the same protocol as for the first year of the study.

\section{Patients maintained in IFX}

As alluded previously, in order to determine the effectiveness of switching IFX to GLM and calculate cost of annual treatment, data in GLM-treated patients were compared with a parallel group of UC patients, matched for age, gender, extent of disease and duration of treatment with the GLM-treated patients, who were attending the Infusion Clinic in our Department. These patients were followed prospectively in the infusion unit 
by adhering to the same protocol as for the GLM-treated patients.

\section{Statistical analysis}

All parameters were tested for normality using the Shapiro-Wilk test. Results are reported as median (interquartile range (IQR)). Differences between data at baseline and 12 months of follow-up, as well as between the GLM- and IFX-treated groups were analyzed using the Wilcoxon signed rank, McNemar's and MannWhitney tests. As this was a pilot study no sample size/ power calculations were performed. Analyses were performed using SPSS software version 17.0 (Chicago, Illinois, USA) and a two-tailed p-value of $<0.05$ was considered statistically significant.

The study was approved by the Ethical review board of our Institution (Evangelismos Hospital Ethics committee approval number : 162/05.04.2016); all patients gave written informed consent. The trial has been registered at clinicaltrials.gov (NCT 02868398). The study protocol conforms to the ethical guidelines of the 1975 Declaration of Helsinki as reflected in a priori approval by the Institution's human research committee.

\section{Results}

\section{Patients included in the study}

From October 2015 to October 2017, 20 UC patients in deep remission after at least 2 years on IFX scheduled maintenance therapy were enrolled in this study and received GLM. Nineteen UC patients in deep remission on $5 \mathrm{mg} / \mathrm{kg}$ of body weight IFX scheduled mono-therapy for $>2$ years were included in the control group. Clinical and disease characteristics of patients and controls at inclusion in the study are shown in table 1 . Nineteen of 20 GLM-treated patients completed the study and all
Table 1. - Patient demographics at inclusion in both group of patients (GLM and IFX maintenance)

\begin{tabular}{|l|c|c|}
\hline & GLM group & IFX group* \\
\hline Males/females (n) & $12 / 7$ & $12 / 7$ \\
\hline Age, median (IQR) years & $42.8(24-61)$ & $42.9(23-63)$ \\
\hline Disease extent (E2/E3) (n) & $11 / 8$ & $11 / 8$ \\
\hline $\begin{array}{l}\text { Disease duration, median } \\
\text { (IQR), months }\end{array}$ & $72(24-198)$ & $88(28-213)$ \\
\hline $\begin{array}{l}\text { Time of IFX administration, } \\
\text { median (IQR), months }\end{array}$ & $26(24-32)$ & $33(24-56)$ \\
\hline Weight, median (IQR), Kg & $75(69-80)$ & $77(74-82)$ \\
\hline Concomitant 5-ASA, n (\%) & $12(63.2 \%)$ & $12(63.2 \%)$ \\
\hline Current smokers, n (\%) & $6(31.6 \%)$ & $7(36.8 \%)$ \\
\hline
\end{tabular}

$*_{p}=$ N.S. (Not Significant)

were still in deep clinical, biomarker and endoscopic remission at the end of the annual follow up. All patients showed excellent tolerance of treatment and neither requested unscheduled visits, nor developed any serious adverse event, nor needed escalation of treatment. All patients maintained a very good quality of life and work productivity and were satisfied with the treatment. One patient became pregnant, 3 months after the first injection of GLM and discontinued treatment at the end of the $2^{\text {nd }}$ trimester while in remission. The clinical, biochemical, endoscopic and quality of life data of GLM-treated patients at inclusion and during follow up is shown in table 2. Serum trough levels of IFX before switching to GLM are also shown in table 2.

In the control group, 18 of 19 patients (95\%) maintained deep clinical, biomarker and endoscopic remission for 1 year. One patient lost response to iv IFX, but clinical remission was recaptured by increasing the dose of IFX to $10 \mathrm{mg} / \mathrm{Kg}$ of body weight every 8 weeks. Thus, there was no difference between patients who were switched to sc GLM and the control group of patients who continued maintenance therapy with i.v. IFX. The clinical, biochemical, endoscopic and quality of life data

Table 2. - Clinical, biochemical, endoscopic and quality of life data at inclusion, at 6 months and 1 year follow up in both the GLM and IFX maintenance group

\begin{tabular}{|c|c|c|c|c|c|c|c|}
\hline & \multicolumn{2}{|c|}{ BASELINE } & \multicolumn{2}{|c|}{$\begin{array}{l}\text { 6-MONTH } \\
\text { FOLLOW UP }\end{array}$} & \multicolumn{2}{|c|}{$\begin{array}{c}1 \text { YEAR } \\
\text { FOLLOW UP }\end{array}$} & \multirow[t]{2}{*}{$\mathrm{P}$} \\
\hline & GLM & IFX & GLM & IFX & GLM & IFX & \\
\hline Total Mayo score, median (IQR) & $1(1-1)$ & $1(0-2)$ & - & - & $1(1-1)$ & $1(0-2)$ & NS \\
\hline Partial Mayo score, median (IQR) & $0(0-1)$ & $0(0-1)$ & $0(0-1)$ & $0(0-1)$ & $0(0-1)$ & $0(0-1)$ & NS \\
\hline Mayo endoscopic sub-score median (IQR) & $0(0-1)$ & $0(0-1)$ & - & - & $0(0-1)$ & $0(0-1)$ & NS \\
\hline Hemoglobin, median (IQR) g/dL & $\begin{array}{c}13.8 \\
(13.5-14.2)\end{array}$ & $\begin{array}{c}13.8 \\
(13.4-14.4)\end{array}$ & $\begin{array}{c}13.8 \\
(13.4-14.3) \\
\end{array}$ & $\begin{array}{c}13.8 \\
(13.4-14.4)\end{array}$ & $\begin{array}{c}13.9 \\
(13.4-14.4)\end{array}$ & $\begin{array}{c}13.7 \\
(13.2-14.4)\end{array}$ & NS \\
\hline ESR, median (IQR) mm/hr & $16(12-19)$ & $17(13-24)$ & $18(13-26)$ & $18(15-26)$ & $18(15-24)$ & $17(13-21)$ & NS \\
\hline Serum CRP median (IQR), mg/L & $0.3(0.2-0.5)$ & $0.3(0.2-0.5)$ & $0.3(0.1-0.5)$ & $0.3(0.2-0.5)$ & $0.3(0.1-0.5)$ & $0.3(0.1-0.5)$ & NS \\
\hline Faecal calprotectin median (IQR), $\mu \mathrm{g} / \mathrm{g}$ & $102(75-140)$ & $122(80-145)$ & $105(94-145)$ & $113(102-144)$ & $110(93-130)$ & $124(93-140)$ & NS \\
\hline IFX trough levels median (IQR) $\mu \mathrm{g} / \mathrm{ml}$ & $\begin{array}{c}5.67 \\
(2.40-8.65) \\
\end{array}$ & $\begin{array}{c}5.80 \\
(2.19-8.65) \\
\end{array}$ & & - & & & NS \\
\hline Short IBDQ, median (IQR) & $69(68-70)$ & $69(68-70)$ & $70(69-70)$ & $69(68-70)$ & $70(69-70)$ & $69(68-70)$ & NS \\
\hline $\begin{array}{l}\text { Work productivity and activity, \% overall } \\
\text { work impairment, median (IQR) }\end{array}$ & $10(0-10)$ & $10(0-10)$ & $0(0-10)$ & $10(0-10)$ & $0(0-10)$ & $10(0-10)$ & NS \\
\hline Greek TSQM, median (IQR) & $54(52-56)$ & $54(52-56)$ & $54(52-57)$ & $54(52-56)$ & $54(52-57)$ & $54(52-56)$ & NS \\
\hline
\end{tabular}

NS = Non Significant. 
of IFX-treated patients at inclusion and during follow up is also shown in table 2.

\section{Long term follow up of patients}

During a median (range) of 3 (2-4) years extension of treatment with GLM, only 2 patients experienced a mildto-moderate flare of UC. The first patient was receiving GLM on a dose of $50 \mathrm{mg}$ per month and clinical remission was recaptured by increasing the dose to $100 \mathrm{mg}$ per month. The second patient was receiving $100 \mathrm{mg}$ GLM per month, but for administrative reasons we were unable to offer re-induction therapy with GLM. This patient was switched back to IFX (induction regimen and then maintenance with $5 \mathrm{mg} / \mathrm{kg}$ body weight) and achieved clinical remission. The patient who stopped GLM, because of pregnancy, resumed treatment with GLM after delivery of a healthy baby at full-term and maintained clinical and biomarker remission in the long term. No serious adverse events from the long term GLM administration were reported.

\section{Treatment cost}

In this study, we have calculated only the direct cost of treatment per patient-year for each treatment strategy, which was 8.737,52 euro for IFX and 7.919,92 euro for GLM.Calculations were based on the sum of all-patient direct treatment costs in each group divided by the number of patients treated in that group. Given the fact that the cost for originator and biosimilar IFX is the same in our Hospital and considering the factors that constitute the indirect cost, GLM is probably a less costly option than IFX.

\section{Discussion}

In this pilot study, $20 \mathrm{UC}$ patients in deep remission were switched from scheduled maintenance therapy with i.v. IFX to sc GLM. Nineteen patients completed the one year follow up and they all remained in deep remission, with an excellent quality of life. The only patient that opted to withdraw from the study, because of pregnancy, was in clinical remission when she stopped treatment. The rate of deep remission in this group was not significantly different from that of a control group matched for age, gender, extent of disease and duration of treatment with the same dose of IFX. In addition, 18 of 20 GLM-treated patients (including the patient who resumed treatment after delivery) who continued on GLM after completion of the study maintained clinical and biomarker remission for a prolonged period of time (median 3 years). In addition, one of the two patients who experienced a flare of UC after the end of the trial recaptured clinical remission by doubling the monthly dose of GLM.

Anti-TNF agents were the first biological therapies employed for the treatment of UC and still have a leading therapeutic position in treatment algorithms for moderate-to-severe UC, refractory to conventional treatment with steroids and/or immunosuppressives (2224). It has been reported that, during IFX maintenance therapy, the minimal trough concentration for patients in remission should be greater than $3 \mu \mathrm{g} / \mathrm{ml}$ (25). However, as there are not universally accepted cut off levels of IFX associated with deep remission in UC, it is not unusual that supposedly "subtherapeutic" IFX levels are associated with deep remission. For instance, although much higher levels are required during induction of remission treatment in active UC, levels of IFX $>2.1 \mu \mathrm{g} / \mathrm{ml}$ were associated with early mucosal healing at week 14, in a retrospective study from Leuven (26), indicating that a very wide range of IFX trough levels may be associated with mucosal healing. In our study, the median IFX trough levels in our two group of patients were $5.67 \mu \mathrm{g} / \mathrm{ml}$ and $5.80 \mu \mathrm{g} / \mathrm{ml}$. Furthermore it should be pointed out that IFX therapy is associated with a considerable financial burden on health systems (27). Scheduled iv IFX treatment is associated with higher rates of absenteeism, work-load burden to Infusion Units, higher rates of infusion-related allergic reactions, loss of response, and need for treatment escalation. Collectively, all these may increase dramatically the all source cost of treatment (28). Furthermore, although ironically this study was conceived at a time prior to the COVID-19 pandemic, it offers a valid therapeutic option for patients with UC in deep remission on IFX maintenance therapy who have not access to IFX sc therapy and who should not be exposed to the risks of a hospital environment during the COVID-19 period (29). Our results provide evidence that switching these stable patients from iv IFX to sc GLM is a safe and effective alternative.

It may be argued that i.v. therapy with IFX provides the advantages of relatively stable bioavailability, flexible dose adjustments and higher patient adherence to and compliance with treatment. However, although this is self-evident for patients with acute severe UC (22), it may not hold true for patients in prolonged deep remission whereby the crucial question is whether patients should continue the same treatment or receive cycles of treatment or switch to a more convenient and less costly treatment (30). Indeed, sc anti-TNFs are generally preferred by patients as they provide more autonomy. For Health Systems and Infusion Units, it is also undoubtedly a relief, as sc treatment reduce considerably the all source cost of treatment and lifts the huge work load, respectively (31). With regards to direct cost of treatment, although it varies between countries and occasionally between Health Authorities within each country, in our center the annual per patient cost of treatment with GLM was slightly less expensive than with IFX. It has to be noted though, that the actual cost in this study has been calculated for patients who continue treatment with the approved dose regimen of IFX and GLM, without any loss of response and/or dose escalations and that in the Public Section of our National 
Health System there are no administrative costs for infusion sessions.

To our knowledge this is the first study to address the effectiveness of switching from an i.v. to a sc administered anti-TNF agent in UC patients in prolonged deep remission. A few years ago an open label, randomized clinical trial demonstrated that elective switching from IFX to ADA in CD patients in remission was associated with significantly higher rates of loss of tolerance and efficacy within 1 year compared with patients who continued IFX treatment (47\% vs $16 \%$ ) (32). On the contrary, another study showed that $72 \%$ of patients with stable CD who switched from IFX to ADA continued treatment with ADA beyond 54 weeks. Eight patients discontinued ADA therapy due to disease activity $(n=3)$, side effects $(n=4)$ or general symptoms $(n=1)$, while after discontinuation of ADA, 4 patients switched back to IFX and no infusion reactions occurred (33). In our study, we chose to electively switch UC patients from IFX to GLM rather than ADA maintenance therapy, since the former has shown high treatment-persistence in the PURSUIT study $(9,10)$ and in real-life clinical settings $(34)$. Our study has also included endoscopic remission as part of deep remission, which can be more easily and accurately assessed in UC than in CD because the disease almost invariably affects the distal colon and rectum.

Another critical point in our study is that patients who were switched to GLM received an induction scheme whereas patients on IFX in the control group continued the usual maintenance therapy. Although this may give an advantage to the switched group we thought that patients should achieve adequate levels of GLM before they go onto maintenance therapy and we do not think that the carry over effect of the induction regimen could last for one year.

Limitations of our study are the small number of patients and lack of a properly randomized control group. This was inevitable in view of the design of this trial, as single-center, pilot study, the strict inclusion criteria and the long period of recruitment. Nevertheless, this study mirrors clinical practice in several countries and may attract attention because IBD patients should be kept away from unsafe hospital environments in the era of the COVID-19 pandemic. Furthermore, we truly cannot exclude the possibility that switching to GLM may undermine future effectiveness of IFX due to development of immunogenicity. However, as our patients were in deep clinical, biomarker and endoscopic remission with adequate trough levels of IFX, development of immunogenicity is not very likely and if needed restart of IFX may be possible. It could also be argued that switching to another biologic agent of the same class in patients in remission, solely for administrative reasons, will be soon less attractive especially because sc formulations of IFX will become available soon. Nonetheless, since this pilot study shows some evidence that switching from IFX iv to GLM sc is effective and safe one can reasonably assume that this may also be true (if not safer) for switching between IFX iv and sc. On the other hand, advantages of our study were its prospective nature, the single center design and execution which renders the recruited patient population more homogenous and less prone to selection bias and the application of a real-life monitoring protocol of patients.

In conclusion, this pilot study indicates that elective switching from IFX to GLM is effective in maintaining long-term deep remission in UC patients who were in deep remission on IFX scheduled maintenance therapy and calls for large randomized clinical trials.

\section{Conflicts of interest}

N. Viazis, Ch. Pontas, A. Manolakis:, G. Karampekos, E. Tsoukali, M. Galanopoulos:, K. R. Koustenis, E. Arcavlis, M. Gazouli, G. J. Mantzaris : none.

\section{Acknowledgments}

This study was supported by a grant received by the Hellenic Group for the study of IBD.

\section{References}

1. PEYRIN-BIROULET L, SANDBORN W, SANDS B, REINISCH W, BEMELMAN W, BRYANT RV, et al. Selecting Therapeutic Targets in Inflammatory Bowel Disease (STRIDE): Determining Therapeutic Goals for Treat-to-Target. Am. J. Gastroenterol. 2015, 110(9) :1324-38.

2. MOLANDER P, KEMPPAINEN H, ILLUS T, SIPPONEN T. Long term deep remission during maintenance therapy with biological agents in inflammatory bowel diseases. Scand. J. Gastroenterol. 2020 Jan, 55(1) : 34-40.

3. PANTAVOU K, YIALLOUROU A, PIOVANI D, EVRIPIDOU D, DANESE S, PEYRIN-BIROULET L, et al. Efficacy and safety of biologic agents and tofacitinib in moderate-to-severe ulcerative colitis: a systematic overview of meta-analyses. United European Gastroenterol. J. 2019, 7(10) : 1285-1303.

4. GISBERT JP, GONZALEZ-LAMA Y, MATE' J. Systematic review : infliximab therapy in ulcerative colitis. Aliment. Pharmacol. Ther. 2007, 25 : 19-37.

5. RUTGEERTS P, SANDBORN WJ, FEAGAN BG, REINISCH W, OLSON A, JOHANNS J, et al. Infliximab for induction and maintenance therapy for ulcerative colitis. N. Engl. J. Med. 2005, 353 : 2462-2476.

6. LAHARIE D, BOURREILLE A, BRANCHE J, ALLEZ M, BOUHNIK Y, FILIPPI J, et al. Groupe d'Etudes Thérapeutiques des Affections Inflammatoires Digestives. Long term outcome of patients with steroidrefractory acute severe UC treated with ciclosporin or infliximab. Gut 2018 Feb, 67(2) : 237-243.

7. SANDBORN WJ, VAN ASSCHE G, REINISCH W, COLOMBEL JF, D'HAENS G, WOLF DC, et al. Adalimumab induces and maintains clinical remission in patients with moderate to-severe ulcerative colitis. Gastroenterology 2012, $142:$ 257-65.

8. COLOMBEL JF, SANDBORN WJ, GHOSH S, WOLF DC, PANACCIONE R, FEAGAN B, et al. Four-year maintenance treatment with adalimumab in patients with moderately to severely active ulcerative colitis: Data from ULTRA 1, 2, and 3. Am. J. Gastroenterol. 2014, 109 : 1771-1780.

9. SANDBORN WJ, FEAGAN BG, MARANO C, ZHANG H, STRAUSS R, JOHANNS J, et al. PURSUIT-SC Study Group. Subcutaneous golimumab induces clinical response and remission in patients with moderate-to-severe ulcerative colitis. Gastroenterology 2014, 146 : 85-95.

10. SANDBORN WJ, FEAGAN BG, MARANO C, ZHANG H, STRAUSS R, JOHANNS J, et al. PURSUIT-Maintenance Study Group. Subcutaneous golimumab maintains clinical response in patients with moderate-to-severe ulcerative colitis. Gastroenterology 2014, 146 : 96-109.

11. VAN DER VALK M, MANGEN M, SEVERS M, VAN DER HAVE M, DIJKSTRA G, VAN BODEGRAVEN A, et al and COIN study group and the Dutch Initiative on Crohn and Colitis. Evolution of Costs of Inflammatory Bowel Disease over Two Years of Follow-Up. PLoS One 2016, 11(4) : e0142481. 
12. LONG G, TATRO A, OH Y, REDDY S, ANANTHAKRISHNAN A. Analysis of Safety, Medical Resource Utilization, and Treatment Costs by Drug Class for Management of Inflammatory Bowel Disease in the United States Based on Insurance Claims Data. Adv. The. 2019, 36(11) : 3079-3095.

13. VASUDEVAN A, GIBSON P, VAN LANGENBERG D. Systematic Review : Cost-effective Strategies of Optimizing Anti-tumor Necrosis and Immunomodulators in Inflammatory Bowel Disease. Inflamm. Bowel. Dis. 2019 Aug 20, 25(9) : 1462-1473.

14. MAGRO F, GIONCHETTI P, ELIAKIM R, ARDIZZONE S, ARMUZZI A, BARREIRO-DE-ACOSTA M, et al. European Crohn's and Colitis Organisation (ECCO). Third European Evidence-based Consensus on Diagnosis and Management of Ulcerative Colitis. Part 1: Definitions, Diagnosis, Extra-intestinal Manifestations, Pregnancy, Cancer Surveillance, Surgery, and Ileo-anal Pouch Disorders. J. Crohns Colitis 2017, 11(6) : 649670.

15. SILVERBERG M, SATSANGI J, AHMAD T, ARNOTT I, BERNSTEIN C, BRANT S, et al. Toward an integrated clinical, molecular and serological classification of inflammatory bowel disease: Report of a Working Party of the 2005 Montreal World Congress of Gastroenterology. Ulcerative colitis clinical classification. Can. J. Gastroenterol. 2005, 19(Suppl. A) : 9A-13A.

16. D'HAENS G, SANDBORN WJ, FEAGAN BG, GEBOES K, HANAUER $\mathrm{SB}$, IRVINE EJ, et al. A review of activity indices and efficacy end points for clinical trials of medical therapy in adults with ulcerative colitis. Gastroenterology 2007, 132 : 763-86.

17. LASSON A, OHMAN L, STOTZER P, et al. Pharmacological intervention based on fecal calprotectin levels in patients with ulcerative colitis at high risk of a relapse: A prospective, randomised, controlled study. United European Gastroenterol. J. 2015, $3:$ : 72-9.

18. OSTERMAN M, ABERRA F, CROSS R, LIAKOS S, McCABE R, SHAFRAN I, et al. DEAR Investigators. Mesalamine dose escalation reduces fecal calprotectin in patients with quiescent ulcerative colitis. Clin. Gastroenterol. Hepatol. 2014, 12 : 1887-93.

19. KAPPELMAN M, LONG M, MARTIN C, DEWALT D, KINNEER P, CHEN W, et al. Evaluation of the patient-reported outcomes measurement information system in a large cohort of patients with inflammatory bowel diseases. Clin. Gastroenterol. Hepatol. 2014, 12, 1315-1323.

20. TRAVIS S, FEAGAN B, PEYRIN-BIROULET L, PANACCIONE R, DANESE S, LAZAR A, et al. Effect of Adalimumab on Clinical Outcomes and Health-related Quality of Life Among Patients with Ulcerative Colitis in a Clinical Practice Setting: Results from InspirADA. J. Crohn's Colitis 2017, $11: 1317-1325$.

21. PAGKALOS E, THANOPOULOU A, SAMPANIS C, BOUSBOULAS S, MELIDONIS A, TENTOLOURIS N, et al. The real life effectiveness and care patterns of type 2 diabetes management in Greece. Exp. Clin. Endocrinol. Diabetes 2018, 126(1) : 53-60.

22. BOSSUYT P. BAERT F. COENEGRACHTS J, DE VOS M, DEWIT O, FERRANTE M, et al. Ulcerative colitis treatment: an insight into daily clinical practice. Acta Gastroenterol. Belg. 2019, 82(3) : 365-372.
23. VICKERS A, AINSWORTH C, MODY R, BERGMAN A, LING C, MEDJEDOVIC J, et al. Systematic Review with Network Meta-Analysis: Comparative Efficacy of Biologics in the Treatment of Moderately to Severely Active Ulcerative Colitis. PLOS ONE| DOI:10.1371/journal.pone.0165435 October 24, 2016

24. DANESE S, FIORINO G, PEYRIN-BIROULET L, LUCENTEFORTE E, VIRGILI G, MOJA L, et al. Biological agents for moderately to severely active ulcerative colitis: a systematic review and network meta-analysis. Ann. Intern. Med. 2014, 160 : 704-711.

25. PAPAMICHAEL $K$, CHEIFETZ A, MELMED G, IRVING P, VANDE CASTEELE N, KOZUCH P, et al. Appropriate therapeutic drug monitoring of biologic agents for patients with inflammatory bowel diseases. Clin. Gastroenterol. Hepatol. 2019, 17(9) : 1655-1668.

26. PAPAMICHAEL K, CHACHU KA, VAJRAVELU RK, VAUGHN BP, NI J, OSTERMAN MT, CHEIFETZ AS. Improved long term outcomes of patients with inflammatory bowel disease receiving proactive versus reactive monitoring of serum concentrations of infliximab Clin. Gastroenterol. Hepatol. 2017 Oct, 15(10) : 1580-1588.

27. COHEN R, YU A, WU E, XIE J, MULANI P, CHAO J. Systematic review: the costs of ulcerative colitis in Western countries. Aliment. Pharmacol. Ther 2010, $31: 693-707$.

28. SUSSMAN D, KUBILIUN N, MULANI P, CHAO J, GILLIS C, YANG M, et al. Comparison of medical costs among patients using adalimumab and infliximab: a retrospective study (COMPAIRS). Inflamm. Bowel Dis. 2012, 18 : 2043-2055.

29. RUBIN D, FEUERSTEIN J, WANG A, COHEN R. AGA clinical practice update on management of Inflammatory Bowel Disease during the COVID-190 pandemic: Expert commentary. Gastroenterology $2020 \mathrm{Apr} 10$, pii: S0016-5085(20)30482-0.

30. BOLIN K, HERTERVIG E, LOUIS E. The cost effectiveness of biological therapy cycles in the management of Crohn's Disease. J. Crohns Colitis 2019 13(10) : 1323-1333.

31. BOSCHETTI G, NANCEY S, DANIEL F, PARIENTE B, LEREBOURS E, DUCLOS B, et al. GETAID. Costs of Crohn's disease according to severity states in France: a prospective observational study and statistical modelling over 10 years. Inflamm. Bowel Dis. 2016 Dec, 22(12) : 2924-2932.

32. VAN ASSCHE G, VERMEIRE S, BALLET V, GABRIELS F, NOMAN M, D'HAENS G, et al. Switch to adalimumab in patients with Crohn's disease controlled by maintenance infliximab: prospective randomised SWITCH trial. Gut 2012, 61 : 229-234.

33. HOENTJEN F, HAARHUIS B, DRENT J, DE JONG D. Elective switching from infliximab to adalimumab in stable Crohn's disease. Inflamm. Bowel Dis. 2013, 19 : 761-766.

34. TAXONERA C, RODRIGUEZ C, BERTOLETTI F, MENCHÉN L, ARRIBAS J, SIERRA M, et al. Clinical outcome of golimumab as first, second or third anti-TNF agent in patients with moderate-to-severe ulcerative colitis. Inflamm. Bowel Dis. 2017, 23 : 1394-1402. 